\title{
Durvalumab for the management of urothelial carcinoma: a short review on the emerging data and therapeutic potential
}

This article was published in the following Dove Medical Press journal:

OncoTargets and Therapy

\section{Capucine Baldini \\ Stéphane Champiat \\ Perrine Vuagnat \\ Christophe Massard}

Drug Development Department, Gustave Roussy Cancer Campus, Université Paris-Saclay, Villejuif, France
Correspondence: Christophe Massard Drug Development Department (DITEP), Gustave Roussy, Université Paris-Sud, Université Paris-Saclay, II 4 rue Edouard Vaillant 94800, Villejuif, France Email christophe.massard@ gustaveroussy.fr

\begin{abstract}
Urothelial carcinoma (UC) is the second most frequent urogenital malignancy with high incidence in the United States and Europe. Despite poor prognosis, new treatments have emerged with great efficacy and safety such as immune checkpoint inhibitors. Durvalumab, an anti Programmed Death Ligand 1, has been given breakthrough in UC in 2017 in patients who have disease progression during or following platinum-containing chemotherapy or who have disease progression $<12$ months after neoadjuvant or adjuvant treatment with platinumcontaining chemotherapy. Food and Drug Administration approval was given on the results of the Phase I/II study of MEDI 4736. In this article, we will review available data on durvalumab in the treatment of locally advanced and metastatic UC and discuss therapeutic potential.

Keywords: immunotherapy, PD-L1 inhibitor, durvalumab, urothelial carcinoma, bladder cancer
\end{abstract}

\section{Introduction}

Urothelial carcinoma (UC) also known as transitional cell carcinoma is the ninth most common cancer worldwide with 430,000 new cases and 165,000 deaths in 2012. ${ }^{1,2}$ In Europe, the incidence is high with 151,297 new cases in 2012 and 52,411 deaths. ${ }^{2}$ Despite the poor prognosis of the disease and the $30 \%$ rate of muscle-invasive carcinoma at diagnosis, treatment has remained the same for decades. The cornerstone of metastatic or unresectable disease was platinum-based chemotherapy. The combination of methotrexate, vinblastine, doxorubicin, and cisplatin (M-VAC) regimen has been considered for first-line therapy in fit patients for 30 years with objective response rates (ORR) around $50 \%-70 \%$. The association of gemcitabine and cisplatin (GC) has been compared to M-VAC in a Phase III study, showing no improvement in overall survival (OS; M-VAC 14.8 months vs GC 13.8 months), but the study was not powered enough to show equivalence between the two regimens. However, the better safety profile led to an approval of GC as an equivalent of M-VAC. ${ }^{3}$ These chemotherapy regimens are tailored for fit patients with good performance status (PS) and adequate renal function. However, $25 \%-50 \%$ of patients with UC are not eligible for cisplatin-based therapies because of age-related comorbidities and epidemiology of the disease. ${ }^{4,5}$

UCs are immunogenic tumors with a high mutational load that can be targeted by immunotherapy ${ }^{6,7}$ Moreover, intravesical Bacille Calmette-Guerin, an immunotherapy, has been used since 1990 to reduce recurrence in nonmuscle-invasive bladder cancer. ${ }^{8}$

Several immune checkpoint blockers have been given breakthrough in UC since 2016 with promising results (Table 1) ${ }^{9-12}$ In this review, we will focus on the use of durvalumab, an anti Programmed Death Ligand 1 (PD-L1) in UC. 
Table I Immune checkpoint blockers with FDA breakthrough approval

\begin{tabular}{|l|l|l|l|l|l|}
\hline Drugs & Trial & Setting & Patients & Results (ITT) & Grade 3-4 AE \\
\hline $\begin{array}{l}\text { Atezolizumab } \\
\text { MPDL3280A }\end{array}$ & $\begin{array}{l}\text { Phase III IMvigor-2II } \\
\text { NCT023002807 }\end{array}$ & $\begin{array}{l}\text { Second-line post } \\
\text { platinum therapy }\end{array}$ & $\mathrm{n}=93 \mathrm{I}$ & $\begin{array}{l}\text { OS: II.I months vs } \\
\text { I0.6 months } \\
\text { ORR: I3\% vs I3\% }\end{array}$ & $20 \%$ \\
\hline $\begin{array}{l}\text { Pembrolizumab } \\
\text { MK3475 }\end{array}$ & $\begin{array}{l}\text { Phase III } \\
\text { KEYNOTE-045 } \\
\text { NCT02256436 }\end{array}$ & $\begin{array}{l}\text { Second-line post } \\
\text { platinum therapy }\end{array}$ & $\mathrm{n}=542$ & $\begin{array}{l}\text { OS: } 10.3 \text { months vs } \\
7.4 \text { months } \\
\text { ORR: } 21 \% \text { vs II\% }\end{array}$ & $15 \%$ \\
\hline Nivolumab & $\begin{array}{l}\text { Phase II } \\
\text { Checkmate-275 }\end{array}$ & $\begin{array}{l}\text { Second-line post } \\
\text { platinum therapy }\end{array}$ & $\mathrm{n}=270$ & $\begin{array}{l}\text { OS: } 8.7 \text { months } \\
\text { ORR: } 20 \%\end{array}$ & $18 \%$ \\
\hline Avelumab & Phase IB & Post chemotherapy & $\mathrm{n}=44$ & ORR: $18 \%$ & $8 \%$ \\
\hline
\end{tabular}

Abbreviations: AE, adverse event; FDA, Food and Drug Administration; ITT, intention to treat population; ORR, objective response rate; OS, overall survival.

\section{Durvalumab}

Durvalumab (Imfinzi ${ }^{\mathrm{TM}}$, MEDI 4736) is a fully human immunoglobulin G1k monoclonal antibody against PD-L1, which is being developed by Astra Zeneca for cancer treatment (Figures 1 and 2). ${ }^{13,14}$ PD-L1 binds to programmed cell death-1 (PD-1) and CD80 (B7-1) receptors, resulting in inhibition of T-cell function. A broad range of human tumors upregulate PD-L1, evading immune surveillance and antitumor T-cell responses. Durvalumab binds to PD-L1 with high affinity and specificity, blocking its interactions with PD-1 and CD80, resulting in enhanced activation of T-cells against tumor cells (TCs). It does not bind to PD-L2.

Durvalumab is given every 2 weeks intravenously at $10 \mathrm{mg} / \mathrm{kg}$ over 60 minutes. Pharmacodynamics parameters showed a concentration-dependent inhibition of PD-L1 in an anti-CD3-based T-cell activation assay and a mixed lymphocyte reaction assay..$^{14}$ Exposure to durvalumab increases dose-proportionally at $\mathrm{C} 3 \mathrm{mg} / \mathrm{kg}$ in cancer patients, with steady-state levels observed at around 16 weeks. ${ }^{15}$ Durvalumab clearance decreases over time but is not considered clinically relevant; the geometric mean terminal half-life of durvalumab is around 17 days. ${ }^{15}$ The pharmacokinetics of durvalumab are not affected by age (19-96 years), body-weight (34-149 kg), sex, race, tumor type, PS, levels of albumin, lactate dehydrogenase, creatinine or soluble PD-L1, mild or moderate renal impairment (creatinine clearance $60-89$ and $30-59 \mathrm{~mL} /$ minute, respectively) or mild hepatic impairment (bilirubin $\leq$ upper limit of normal [ULN] and AST $>$ ULN or bilirubin $>1.0-1.5$ times ULN and any AST). No data are available in severe renal or hepatic impairment.

\section{Efficacy and safety in UC}

Durvalumab was evaluated in a Phase I/II study in all solid tumors (Table 2). ${ }^{16}$ Subjects received durvalumab $10 \mathrm{mg} / \mathrm{kg}$ every 2 weeks until disease progression, unacceptable toxicities, or a maximum duration of 12 months. After the treatment course, patients were offered a retreatment course of another 12 months. The initial 20 patients were enrolled regardless of PDL-1 expression. PD-L1 was defined as positive if either $\geq 25 \%$ of $\mathrm{TC}$ or $\geq 25 \%$ of immune cells (IC) expressed PD-L1. In UC patients, most of them (93.4\%) had received $\geq 1$ prior lines of platinum-based chemotherapy, $29.5 \%$ had liver metastases. ${ }^{16}$

In the expansion phase with a cohort of 182 patients with UC, the ORR was $31.0 \%$ (95\% CI, 17.6-47.1) overall in the

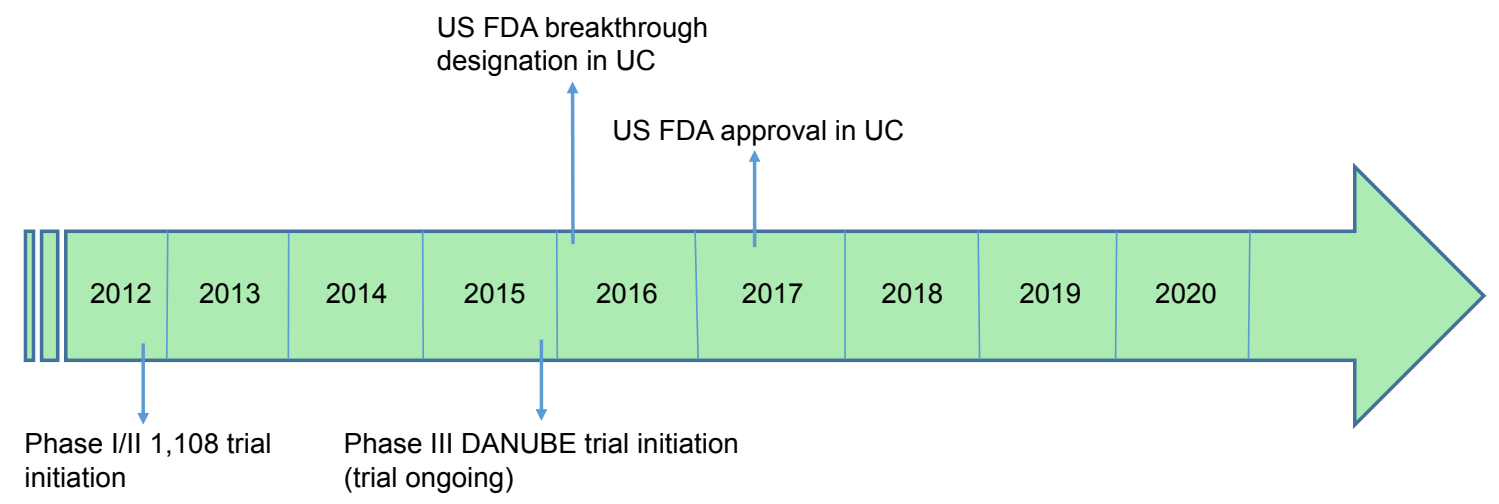

Figure I Development of durvalumab - key dates.

Abbreviation: UC, urothelial carcinoma. 

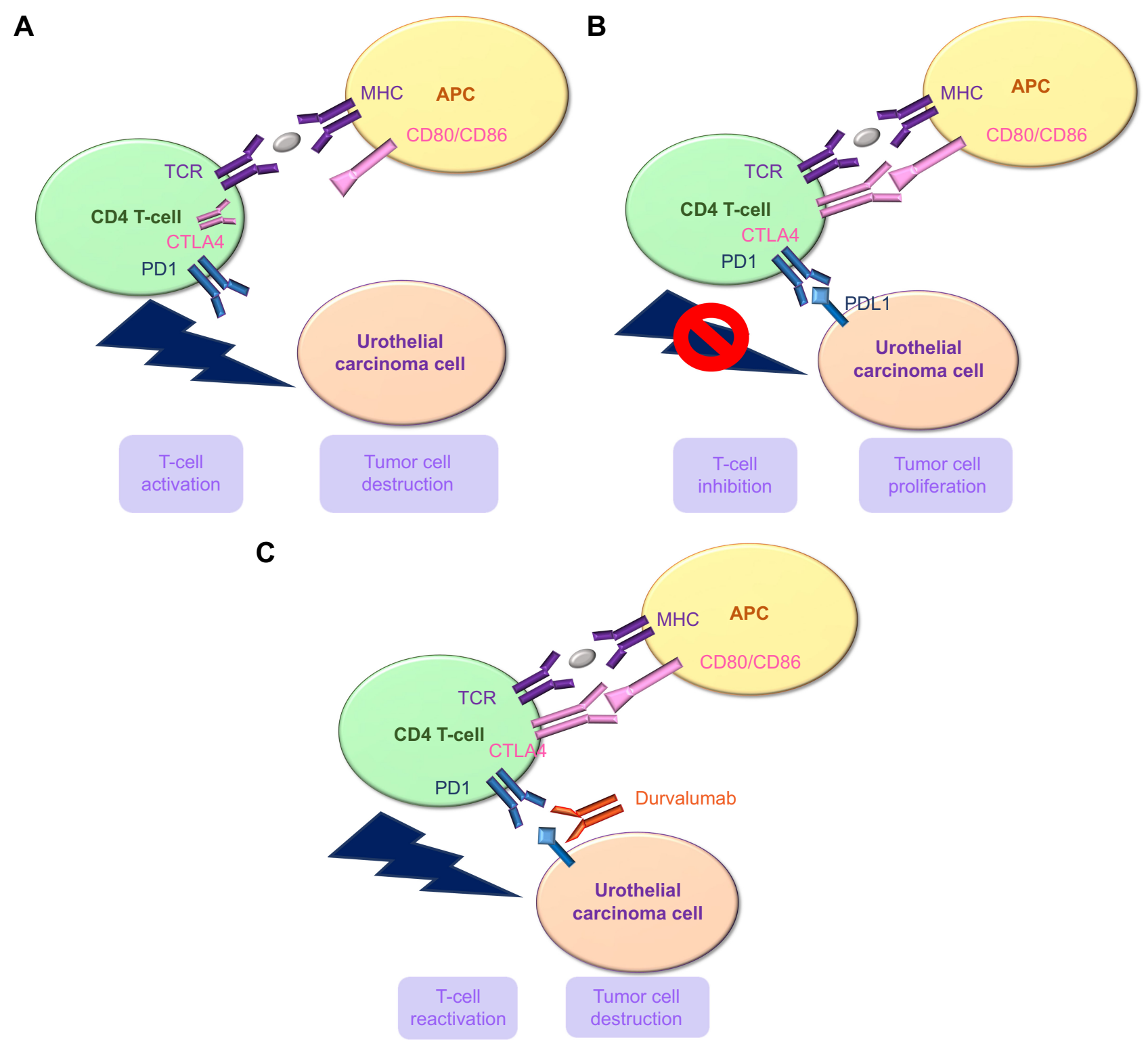

Figure 2 Mechanism of action of durvalumab: normal immune response (A); tumor immune invasion (B); and immune response restoration (C).

Abbreviations: MHC, major histocompatibility complex; APC, antigen presenting cell; TCR, T cell receptor; PDI, programmed death receptor; CTLA4, cytotoxic T-lymphocyte-associated protein 4.

42 response-evaluable patients. The ORR was $46.4 \%$ in the PD-L1-positive subgroup and $0 \%$ in the PD-L1-negative subgroup, and disease control rate at 12 months was $57.1 \%$ and $28.6 \%$, respectively. Patients showed rapid and durable response. Median follow-up of response-evaluable patients was 6.5 months (range, $0.8-14.8$ months). The median time to response was 6.3 weeks (95\% CI, 5.6-12.1 weeks) in the 13 responding patients, and median duration of response has not been reached (range, $4.1+$ to $49.3+$ weeks). ${ }^{16}$ The updated results showed an ORR of $17.8 \%$ (34/191; 95\% CI, 12.7-24.0), including seven complete responses. The ORRs were $27.6 \%$ ( $n=27 ; 95 \%$ CI, 19.0-37.5) in PD-L1 high patients and 5.1\% (n=4; 95\% CI, 1.4-12.5) in PD-L1 low or negative patients. Median time to response was 1.41 months (range, 1.2-7.2). Median duration of response in the as-treated population had not been reached at data cutoff (range, $\geq 0.9$ to $\geq 19.9$ months). ${ }^{17}$ The median OS was 18.2 months $(95 \%$ CI, 8.1-not estimable) in the as-treated population and 20.0 months (95\% CI, 11.6-not estimable) and 8.1 months (95\% CI, 3.1-not estimable) in PD-L1 high and low or negative patients, respectively. The OS rates at 6, 9, and 12 months were 64\% (95\% CI, 56-71), 57\% (95\% CI, 47-66), and 55\% (95\% CI, 44-65), respectively, in the as-treated population. ${ }^{17}$

Durvalumab showed manageable safety profile. Grade 3 or 4 treatment-related adverse events (AEs) occurred in $6.8 \%$ of the patients. Treatment-related AEs leading to death occurred in 2 of 191 patients $(1.0 \%)$ with one autoimmune hepatitis and one pneumonitis. Regarding adverse 
Table 2 Trials evaluating durvalumab in UC

\begin{tabular}{|c|c|c|c|c|}
\hline & Trial & Setting & Results & References \\
\hline \multirow[t]{2}{*}{$\begin{array}{l}\text { Durvalumab } \\
\text { monotherapy }\end{array}$} & \multirow[t]{2}{*}{ NCTOI693562; Phase I and II } & \multirow[t]{2}{*}{ Second line } & $\begin{array}{l}\mathrm{n}=6 \mathrm{I} \text { ( } 42 \text { response-evaluable at } 6.5 \text { months } \mathrm{mFU}) \\
\text { - ORR } 3 \text { I\% ( } 46 \% \text { in PD-LI TC-positive and/or IC-positive } \\
\text { vs } 0 \% \text { in PD-LI TC-negative and/or IC-negative) } \\
\text { - } \mathrm{mDOR} \text { NR at } 6.5 \text { months mFU } \\
\text { - Grade } \geq 3 \text { TRAEs in } 5 \%\end{array}$ & $\begin{array}{l}\text { Massard } \\
\text { et } \mathrm{al}^{16}\end{array}$ \\
\hline & & & $\begin{array}{l}\mathrm{n}=\text { I9I (I77 with evaluable TC PD-LI; } 5.8 \text { months mFU) } \\
\text { - ORR I8\% (28\% TC PD-LI high, 5\% TC PD-LI low, and } \\
\text { 2I\% TC PD-LI NE) } \\
\text { - } \text { mDOR NR } \\
\text { - Grade } 3 \text { and/or } 4 \text { AEs in } 7 \%\end{array}$ & Powles et al ${ }^{9}$ \\
\hline $\begin{array}{l}\text { Durvalumab + } \\
\text { MEDI0680 }\end{array}$ & NCT02I I8337; Phase I & Second line & $\begin{array}{l}\mathrm{n}=30 \text { (solid malignancies; } 29 \text { response-evaluable) } \\
\text { - } \mathrm{mFU} 7.2 \text { months } \\
\text { - ORR } 31 \% \text {; one CR (UC) and eight PR } \\
\text { - Grade } \geq 3 \text { TRAEs in } 20 \%\end{array}$ & Hamid et $\mathrm{a}^{46}$ \\
\hline
\end{tabular}

Abbreviations: $\mathrm{AE}$, adverse event; $\mathrm{CR}$, complete response; IC, immune cell; $\mathrm{mDOR}$, median duration of response; $\mathrm{mFU}$, median follow-up; NE, not evaluable; NR, not reached; ORR, objective response rate; PD-LI, programmed death ligand I; PR, partial response; TC, tumor cell; TRAE, treatment-related adverse event; UC, urothelial carcinoma.

events of special interest (AESIs), they occurred in $34.6 \%$ and were mostly grade 1 or 2 . Their cumulative incidence seemed to plateau at around 32 weeks. Almost 5\% experienced treatment-related grade $3 / 4$ AESIs (hepatic and skin events). ${ }^{17}$

Based on these first results, the Food and Drug Administration (FDA) granted accelerated approval to durvalumab in May 2017 for patients with locally advanced or metastatic $\mathrm{UC}$ who have disease progression during or following platinum-containing chemotherapy or who have disease progression $<12$ months after neoadjuvant or adjuvant treatment with platinum-containing chemotherapy.

\section{Biomarkers and companion test}

Finding robust biomarkers that could help select patients who will benefit from immunotherapy is one of the main challenges with immune checkpoint blockers. Mutational burden and high clonal neoantigens have shown great correlation with efficacy of diverse anti-PD-L1/PD-1 and anti-CTLA4 drugs. ${ }^{18,19}$ PD-L1 expression was one the first biomarkers investigated in multiple tumor types. ${ }^{20-22}$ In the Phase I/II trial of durvalumab, PD-L1 testing was required. PD-L1 status was determined using a companion test Ventana 2P263 assay. Tumor was considered PD-L1 high with expression on $\geq 25 \%$ of either IC or TC. The first 20 patients were enrolled regardless of their PD-L1 status but subsequent patients were required to have $5 \%$ of $\mathrm{PD}-\mathrm{L} 1$ expression on TCs. ${ }^{16}$ FDA approval was also granted with the companion test as a complementary diagnostic for the assessment of the PD-L1 protein in formalin-fixed, paraffin-embedded UC tissue. At ASCO 2018, the results of PD-L1 expression in TC or IC on the outcomes of OS, PFS, objective response rate (ORR), best percentage tumor change, and tumor shrinkage
15 months after last subject randomization were presented. Both tumor-infiltrating ICs and TC PD-L1 were linked to higher ORR, and PD-L1 tumor-infiltrating ICs were associated with better survival in patients treated with durvalumab. Remarkably, PD-L1 tumor-infiltrating ICs had a higher impact on response to durvalumab than PD-L1 TC, demonstrating a significant association with OS, PFS, ORR, and tumor shrinkage. The results of this study for patients treated with durvalumab for bladder cancer suggest that a cutoff/ algorithm using PD-L1 TC 25\%/PD-L1 tumor-infiltrating IC 25\% (TC25\%/IC25\%) provides optimal predictive value based on efficacy and prevalence of the biomarker $(\mathrm{HR}=0.46$; 90\% CI: $0.33-0.64) .{ }^{23}$

\section{Future perspectives}

Durvalumab is currently under investigation in combination with other agents such as tremelimumab (anti-CTLA4) in various tumor types (Table 3 ). First results were presented at ASCO 2018 for the combination of durvalumab and tremelimumab in patients with localized, high-risk, muscle-invasive bladder carcinoma who are ineligible for cisplatin-containing chemotherapy due to decreased renal function, neuropathy, hearing loss, or heart failure (NCT02812420). Patients received durvalumab $(1,500 \mathrm{mg})$ plus tremelimumab $(75 \mathrm{mg})$ on weeks 1 and 5 and then underwent surgery at weeks 9-11. Twelve patients were enrolled and six completed radical cystectomy; three (50\%) had pathologically complete response; one $(17 \%)$ did not respond; two (33\%) had upstaging of disease. Only 1 of 12 patients developed grade 3 immunerelated toxicity. These promising results showed interesting potential of using immune checkpoint blockers as a neoadjuvant therapy, and results of larger studies are awaited. ${ }^{24}$ 
Table 3 Ongoing studies with durvalumab in UC

\begin{tabular}{|c|c|c|c|}
\hline Drugs & Trial & Setting & Status \\
\hline Durvalumab \pm tremelimumab & $\begin{array}{l}\text { DANUBE } \\
\text { NCT025I624I } \\
\text { Phase III }\end{array}$ & First line & Ongoing \\
\hline Durvalumab + tremelimumab & $\begin{array}{l}\text { NITIMIB } \\
\text { NCT03234I53 } \\
\text { Phase I }\end{array}$ & $\begin{array}{l}\text { Neoadjuvant } \\
\text { Muscle-invasive, high-risk, ineligible for cisplatin-based } \\
\text { chemotherapy }\end{array}$ & Ongoing \\
\hline $\begin{array}{l}\text { Durvalumab } \pm \text { tremelimumab }+ \\
\text { radiation therapy }\end{array}$ & $\begin{array}{l}\text { NCT0360I455 } \\
\text { Phase II }\end{array}$ & $\begin{array}{l}\text { Unresectable, locally advanced, or metastatic urothelial } \\
\text { bladder cancer ineligible or refusing chemotherapy }\end{array}$ & Recruiting Nov 2018 \\
\hline Durvalumab \pm tremelimumab + MVAC & $\begin{array}{l}\text { NEMIO } \\
\text { NCT035497I } 5 \\
\text { Phase I/II }\end{array}$ & Neoadjuvant muscle-invasive UC & Not yet recruiting \\
\hline $\begin{array}{l}\text { Durvalumab } \pm \text { BCG } \\
\text { Durvalumab } \pm \text { radiation therapy }\end{array}$ & $\begin{array}{l}\text { ADAPT-BLADDER } \\
\text { NCT033I7I } 58 \\
\text { Phase } 1 / I I\end{array}$ & BCG-relapsing UC of the bladder & Ongoing \\
\hline Durvalumab & $\begin{array}{l}\text { NCT0290I548 } \\
\text { Phase II }\end{array}$ & BCG-relapsing UC of the bladder & Ongoing \\
\hline Durvalumab + olaparib & $\begin{array}{l}\text { NEODURVARIB } \\
\text { NCT03534492 } \\
\text { Phase II }\end{array}$ & Neoadjuvant bladder carcinoma & Not yet recruiting \\
\hline Durvalumab + BCG vs BCG alone & $\begin{array}{l}\text { POTOMAC } \\
\text { NCT03528694 } \\
\text { Phase III }\end{array}$ & BCG naïve nonmuscle-invasive bladder carcinoma & Ongoing \\
\hline Durvalumab + olaparib & $\begin{array}{l}\text { BAYOU } \\
\text { NCT03459846 } \\
\text { Phase II }\end{array}$ & First-line in platinum-ineligible unresectable stage IV UC & Ongoing \\
\hline Durvalumab + Vicinium & $\begin{array}{l}\text { NCT03258593 } \\
\text { Phase I }\end{array}$ & BCG-relapsing UC of the bladder & Ongoing \\
\hline Durvalumab + tremelimumab vs SoC & $\begin{array}{l}\text { DUTRENEO } \\
\text { NCT03472274 } \\
\text { Phase II }\end{array}$ & Neoadjuvant bladder carcinoma & Not yet recruiting \\
\hline $\begin{array}{l}\text { AZD4547 vs Durvalumab vs AZD4547 + } \\
\text { Durvalumab vs Durvalumab + } \\
\text { Olaparib vs Durvalumab + AZD I775 vs } \\
\text { Durvalumab + Vistusertib }\end{array}$ & $\begin{array}{l}\text { BISCAY } \\
\text { NCT0254666I } \\
\text { Phase lb }\end{array}$ & $\begin{array}{l}\text { Muscle-invasive bladder cancer (urothelial) who have } \\
\text { progressed on prior treatment }\end{array}$ & Ongoing \\
\hline $\begin{array}{l}\text { Durvalumab with radiotherapy then } \\
\text { adjuvant Durvalumab }\end{array}$ & $\begin{array}{l}\text { DUART } \\
\text { NCT0289II6I } \\
\text { Phase I/II }\end{array}$ & Bladder cancer (T2-4, N0-2, M0) & Ongoing \\
\hline $\begin{array}{l}\text { In situ vaccination with tremelimumab } \\
\text { and IV Durvalumab + toll-like receptor } \\
\text { agonist PolyICLC (TLR3 agonist) }\end{array}$ & $\begin{array}{l}\text { NCT02643303 } \\
\text { Phase I/II }\end{array}$ & Bladder cancer & Ongoing \\
\hline Durvalumab + tremelimumab & $\begin{array}{l}\text { NCT028I2420 } \\
\text { Phase II }\end{array}$ & $\begin{array}{l}\text { Muscle-invasive, high-risk UC ineligible for cisplatin- } \\
\text { based neoadjuvant chemotherapy }\end{array}$ & Ongoing \\
\hline $\begin{array}{l}\text { Durvalumab + SoC; Durvalumab + } \\
\text { tremelimumab + SoC; SoC }\end{array}$ & $\begin{array}{l}\text { NILE } \\
\text { NCT03682068 } \\
\text { Phase III }\end{array}$ & Unresectable or metastatic UC & Ongoing \\
\hline
\end{tabular}

Abbreviations: BCG, Bacille Calmette-Guerin; SoC, standard of care chemotherapy; UC, urothelial carcinoma.

In the first-line setting, the DANUBE trial is ongoing in UC testing the combination of durvalumab and tremelimumab. Results of this Phase III trial will be presented soon and hopefully showed increased response rate. Many questions remain on how to better select patients and also improve the number of patients who will benefit from immune checkpoint blockers.
Main perspectives are thus combination therapies with either other immune checkpoint blockers, epigenetic drugs, chemotherapy or radiation therapy and hopefully find robust biomarkers to increase response rate (Table 3). One option is possibly to combine immune checkpoint blockers and the other option is to adapt treatment based on biomarkers. This 
is the purpose of the BISCAY trial (NCT02546661), which is designed to combine Durvalumab with other targeted therapies according to biomarkers. This Phase Ib study is a multiarm trial and is evaluating the combination of durvalumab with AZD4547 (selective inhibitor of the FGFR1, 2, and 3 tyrosine kinases), Olaparib, AZD1775 (WEE1 inhibitor), Vistusertib (mTOR inhibitor), or AZD9150 (STAT3 inhibitor) in patients with UC who have progressed after prior treatment.

Phase III trials are also ongoing in other tumor types, in first, second, and third line in Non-small-cell lung cancer (NSCLC; PEARL NCT03003962, MYSTIC NCT02453282, ARCTIC NCT02352948, PACIFIC NCT02125461) and in Head and Neck Squamous Cell Carcinoma (KESTREL NCT02551159, EAGLE NCT02369874).

Very few data are available in older patients with only subgroup analysis and no geriatric data to better characterize the population. However, the incidence of cancer is increasing in that population. There is a tremendous need for evidence-based medicine data in that population, to better adapt treatment strategies. Indeed, compared with conventional cancer therapies, immunotherapy offers a better safety profile with $<10 \%$ of severe toxicities and is therefore an attractive option in older patients. ${ }^{25,26}$

Due to the low toxicity prolife, the revolution of immune cancer therapy might especially be of great interest in the older population. Nevertheless, at the moment, there is few evidence of efficacy and tolerance of these drugs in the geriatric population. At the same time, a decline of both adaptive and innate immunity is observed with increasing age. ${ }^{27,28}$ This phenomenon, called immunosenescence (IS), is responsible for poor response to vaccination and increased susceptibility to infections. ${ }^{29,30}$

Additionally, increased prevalence of autoimmune disease which is linked with an increase of autoantibodies is observed in older patients. ${ }^{31,32}$ Especially, in older cancer patients, modification of both the IC phenotype (mainly T cell compartment), the immune microenvironment and intracellular communication are the main reasons for dysfunctional immune responses. ${ }^{33-35}$

IS is also associated with a state of chronic low-grade inflammation called inflammaging, responsible for altered level of cytokines. All these reasons urged us to analyze efficacy and toxicity of anti PD-L1 therapy.

Therefore, studies with durvalumab in patients with various solid tumors including UC, aged $>70$ years old incorporating geriatric data to assess safety and efficacy are ongoing.

Moreover, it was recently suggested that a subgroup of patients presents a deleterious acceleration of their cancer disease, defined as hyperprogression in different tumor types such as lung cancers and head and neck cancers. ${ }^{36-39}$ Several biological hypotheses may explain why PD1/PD-L1 blockade may paradoxically lead to this phenomenon, including, expansion of PD1+ Tregs, compensatory T-cell exhaustion, modulation of protumor immune subsets, activation of aberrant inflammation, or activation of an oncogenic pathway. Prospective trials are warranted to validate this new concept. ${ }^{40}$

Improving patient selection for immuno-oncology trials and real-life setting is an active area of research to better identify, in particular, fast progressors. Massard et al developed a tool (FastProgIO) predicting 12-week life expectancy using a multivariate regression method in patients with NSCLC and $\mathrm{UC}$ treated with durvalumab \pm tremelimumab and compared it to existing published scores (Royal Marsden Hospital prognostic score [RMH], Gustave Roussy Immune Score [GRIM], lung immune prognostic index [LIPI]). ${ }^{41-43}$ The performance was assessed by time-dependent true positive rate (TPR) and false positive rate (FPR). FastProgIO includes neutrophils, AST, alkaline phosphatase, and hemoglobin as the predictive markers. At 12 weeks, the TPR for FastProgIO was $73 \%$, (90\% CI: $67 \%-80 \%$ ) vs $69 \%, 65 \%$, and $41 \%$ for RMH, GRIM, and LIPI, respectively. ${ }^{44}$ Furthermore, the FPR of FastProgIO (11\%, 90\% CI: 9.3\%-13\%) was comparable to LIPI (10\%), but better controlled than RMH and GRIM (20\% and $17 \%){ }^{44}$ This score needs to be further validated but can be an interesting option to better select patients eligible for immune-oncology trials.

Finally, new patterns of response to immune checkpoint blockers need to be further investigated and described to improve our understanding of immune checkpoint blockers and improve patient care.

\section{Conclusion}

Durvalumab is a safe and effective therapeutic option in UC and was granted FDA approval in May 2017 based on the results of the Phase I/II trial. Questions remain about the optimal therapeutic strategies in UC with the breakthrough of several anti-PD-1 and anti-PD-L1 recently and new treatments such as FGFR inhibitors. Answers may emerge with the recent molecular characterization of muscle-invasive bladder cancer. ${ }^{45}$ Robertson et al identified five expression subtypes that may be sensitive to different treatments. ${ }^{45}$ This characterization may help practitioners to find optimal strategies for patients. Moreover, results of trials testing combination therapies with immune checkpoint blockers are awaited. Treatment landscape of UC is moving forward, and new therapeutic options will be available in the upcoming future. 


\section{Disclosure}

The authors report no conflicts of interest in this work.

\section{References}

1. Ferlay J, Soerjomataram I, Dikshit R, et al. Cancer incidence and mortality worldwide: sources, methods and major patterns in GLOBOCAN 2012. Int J Cancer. 2015;136(5):E359-E386.

2. Antoni S, Ferlay J, Soerjomataram I, Znaor A, Jemal A, Bray F. Bladder cancer incidence and mortality: a global overview and recent trends. Eur Urol. 2017;71(1):96-108.

3. von der Maase H, Hansen SW, Roberts JT, et al. Gemcitabine and cisplatin versus methotrexate, vinblastine, doxorubicin, and cisplatin in advanced or metastatic bladder cancer: results of a large, randomized, multinational, multicenter, phase III study. J Clin Oncol. 2000;18(17): 3068-3077.

4. Dash A, Galsky MD, Vickers AJ, et al. Impact of renal impairment on eligibility for adjuvant cisplatin-based chemotherapy in patients with urothelial carcinoma of the bladder. Cancer. 2006;107(3):506-513.

5. Sonpavde G, Galsky MD, Latini D, Chen GJ. Cisplatin-ineligible and chemo-ineligible patients should be the focus of new drug development in patients with advanced bladder cancer. Clin Genitourin Cancer. 2014;12(2):71-73

6. Sharma P, Shen Y, Wen S, et al. CD8 tumor-infiltrating lymphocytes are predictive of survival in muscle-invasive urothelial carcinoma. Proc Natl Acad Sci U S A. 2007;104(10):3967-3972.

7. Lawrence MS, Stojanov P, Polak P, et al. Mutational heterogeneity in cancer and the search for new cancer-associated genes. Nature. 2013 499(7457):214-218.

8. Lamm DL, Blumenstein BA, Crawford ED, et al. A randomized trial of intravesical doxorubicin and immunotherapy with bacille CalmetteGuérin for transitional-cell carcinoma of the bladder. $N$ Engl $J$ Med. 1991;325(17):1205-1209.

9. Powles T, Durán I, van der Heijden MS, et al. Atezolizumab versus chemotherapy in patients with platinum-treated locally advanced or metastatic urothelial carcinoma (IMvigor211): a multicentre, open-label, phase 3 randomised controlled trial. Lancet. 2018;391(10122):748-757.

10. Apolo AB, Infante JR, Balmanoukian A, et al. Avelumab, an AntiProgrammed Death-Ligand 1 antibody, in patients with refractory metastatic urothelial carcinoma: results from a multicenter, phase $\mathrm{Ib}$ study. J Clin Oncol. 2017;35(19):2117-2124.

11. Sharma P, Retz M, Siefker-Radtke A, et al. Nivolumab in metastatic urothelial carcinoma after platinum therapy (CheckMate 275): a multicentre, single-arm, phase 2 trial. Lancet Oncol. 2017;18(3):312-322.

12. Bellmunt J, de Wit R, Vaughn DJ, et al. Pembrolizumab as secondline therapy for advanced urothelial carcinoma. N Engl J Med. 2017; 376(11):1015-1026.

13. Ibrahim R, Stewart R, Shalabi A. PD-L1 blockade for cancer treatment: MEDI4736. Semin Oncol. 2015;42(3):474-483.

14. Stewart R, Morrow M, Hammond SA, et al. Identification and characterization of MEDI4736, an antagonistic anti-PD-L1 monoclonal antibody. Cancer Immunol Res. 2015;3(9):1052-1062.

15. U.S. Food and Drug Administration. Durvalumab (Imfinzi) [Internet]. [cité 11 févr 2018]. Available from: https://www.fda.gov/Drugs/ InformationOnDrugs/ApprovedDrugs/ucm555930.htm. Accessed February 11, 2018.

16. Massard C, Gordon MS, Sharma S, et al. Safety and efficacy of Durvalumab (MEDI4736), an Anti-Programmed cell death ligand-1 immune checkpoint inhibitor, in patients with advanced urothelial bladder cancer. J Clin Oncol. 2016;34(26):3119-3125.

17. Powles T, O'Donnell PH, Massard C, et al. Efficacy and safety of Durvalumab in locally advanced or metastatic urothelial carcinoma: updated results from a phase 1/2 open-label study. JAMA Oncol. 2017; 3(9):e172411.

18. McGranahan N, Furness AJS, Rosenthal R, et al. Clonal neoantigens elicit $\mathrm{T}$ cell immunoreactivity and sensitivity to immune checkpoint blockade. Science. 2016;351(6280):1463-1469.
19. Alexandrov LB, Nik-Zainal S, Wedge DC, et al. Signatures of mutational processes in human cancer. Nature. 2013;500(7463):415-421.

20. Ferris RL, Blumenschein G, Fayette J, et al. Nivolumab for recurrent squamous-cell carcinoma of the head and neck. $N$ Engl J Med. 2016; 375(19):1856-1867.

21. Nanda R, Chow LQ, Dees EC, et al. Pembrolizumab in patients with advanced triple-negative breast cancer: phase Ib KEYNOTE-012 study. J Clin Oncol. 2016;34(21):2460-2467.

22. Herbst RS, Baas P, Kim DW, et al. Pembrolizumab versus docetaxel for previously treated, PD-L1-positive, advanced non-small-cell lung cancer (KEYNOTE-010): a randomised controlled trial. Lancet. 2016; 387(10027):1540-1550.

23. Zajac M, Ye J, Mukhopadhyay P, et al. Optimization of PD-L1 algorithm for predicting overall survival (OS) in patients with urothelial cancer (UC) treated with durvalumab monotherapy. J Clin Oncol. 2018 36:15_suppl. 4530-4530.

24. Gao J, Siefker-Radtke AO, Navai N, Campbell MT, Slack R, Guo C, Kamat AM, Matin SF, Papadopoulos JN, Araujo JC, Shah AY. A pilot pre-surgical study evaluating anti-PD-L1 durvalumab (durva) plus antiCTLA-4 tremelimumab (treme) in patients with muscle-Invasive, high-risk urothelial bladder carcinoma who are ineligible for cisplatin-based neoadjuvant chemotherapy. J Clin Oncol. 2018;36:15_suppl. e16524-e16524.

25. Helissey C, Vicier C, Champiat S. The development of immunotherapy in older adults: new treatments, new toxicities? J Geriatr Oncol. 2016; 7(5):325-333

26. Herin $\mathrm{H}$, Aspeslagh $\mathrm{S}$, Castanon E, et al. Immunotherapy phase I trials in patients older than 70 years with advanced solid tumours. Eur J Cancer. 2018;95:68-74.

27. Fulop T, Larbi A, Kotb R, Pawelec G. Immunology of aging and cancer development. Interdiscip Top Gerontol. 2013;38:38-48.

28. Fulop T, Le Page A, Fortin C, Witkowski JM, Dupuis G, Larbi A. Cellular signaling in the aging immune system. Curr Opin Immunol. 2014; 29:105-111.

29. Montgomery RR, Shaw AC. Paradoxical changes in innate immunity in aging: recent progress and new directions. J Leukoc Biol. 2015;98(6):937-943.

30. Fuentes E, Fuentes M, Alarcón M, Palomo I. Immune system dysfunction in the elderly. An Acad Bras Cienc. 2017;89(1):285-299.

31. Silis MP, Pange PJ, Goudevenos J, Moutsopoulos HM. High prevalence of anti-cardiolipin and other autoantibodies in a healthy elderly population. Clin Exp Immunol. 1987;69(3):557-565.

32. Nagele EP, Han M, Acharya NK, DeMarshall C, Kosciuk MC, Nagele RG. Natural Ig G autoantibodies are abundant and ubiquitous in human sera, and their number is influenced by age, gender, and disease. PLoS One. 2013;8(4):e60726.

33. Solana R, Tarazona R, Gayoso I, Lesur O, Dupuis G, Fulop T. Innate immunosenescence: effect of aging on cells and receptors of the innate immune system in humans. Semin Immunol. 2012;24(5):331-341.

34. Tomihara K, Curiel TJ, Zhang B. Optimization of immunotherapy in elderly cancer patients. Crit Rev Oncog. 2013;18(6):573-583.

35. Fülöp T, Larbi A, Pawelec G. Human T cell aging and the impact of persistent viral infections. Front Immunol. 2013;4:271.

36. Champiat S, Dercle L, Ammari S, Massard C, Hollebecque A, PostelVinay S. Hyperprogressive disease is a new pattern of progression in cancer patients treated by Anti-PD-1/PD-L1. Clin Cancer Res. 2017; 23(8):1920-1928.

37. Ferrara R, Mezquita L, Texier M, et al. Hyperprogressive disease in patients with advanced non-small cell lung cancer treated with PD-1/ PD-L1 inhibitors or with single-agent chemotherapy. JAMA Oncol. 2018;4(11):1543-1552.

38. Saâda-Bouzid E, Defaucheux C, Karabajakian A, et al. Hyperprogression during anti-PD-1/PD-L1 therapy in patients with recurrent and/or metastatic head and neck squamous cell carcinoma. Ann Oncol. 2017; 28(7):1605-1611.

39. Kato S, Goodman A, Walavalkar V, Barkauskas DA, Sharabi A, Kurzrock R. Hyperprogressors after immunotherapy: analysis of genomic alterations associated with accelerated growth rate. Clin Cancer Res. 2017;23(15):4242-4250. 
40. Champiat S, Ferrara R, Massard C, et al. Hyperprogressive disease: recognizing a novel pattern to improve patient management. Nat Rev Clin Oncol. 2018;15(12):748-762.

41. Arkenau HT, Barriuso J, Olmos D, et al. Prospective validation of a prognostic score to improve patient selection for oncology phase I trials. J Clin Oncol. 2009;27(16):2692-2696.

42. Bigot F, Castanon E, Baldini C, et al. Prospective validation of a prognostic score for patients in immunotherapy phase I trials: the Gustave Roussy immune score (GRIm-Score). Eur J Cancer. 2017;84: 212-218.

43. Mezquita L, Auclin E, Ferrara R, et al. Association of the lung immune prognostic index with immune checkpoint inhibitor outcomes in patients with advanced non-small cell lung cancer. JAMA Oncol. 2018;4(3): $351-357$.
44. Massard C, Segal NH, Cho DC, et al. Prospective validation of prognostic scores to improve patient selection for immuno-oncology trials. Ann Oncol. 2018;29(suppl_8):viii133-viii148.

45. Robertson AG, Kim J, Al-Ahmadie H, et al. Comprehensive molecular characterization of muscle-invasive bladder cancer. Cell. 2017;171(3): 540.e25-556.e25.

46. Hamid O, Chow LQ, Sanborn RE, Marshall S, Black C, Gribbin M, McDevitt J, Karakunnel JJ, Gray JE. Combination of MEDI0680, an antiPD-1 antibody, with durvalumab, an anti-PD-L1 antibody: A phase 1, open-label study in advanced malignancies. Annals of Oncology. 2016;1:27(suppl_6).

\section{Publish your work in this journal}

OncoTargets and Therapy is an international, peer-reviewed, open access journal focusing on the pathological basis of all cancers, potential targets for therapy and treatment protocols employed to improve the management of cancer patients. The journal also focuses on the impact of management programs and new therapeutic agents and protocols on

\section{Dovepress}

patient perspectives such as quality of life, adherence and satisfaction. The manuscript management system is completely online and includes a very quick and fair peer-review system, which is all easy to use. Visit http://www.dovepress.com/testimonials.php to read real quotes from published authors. 